\title{
Robustness of steel joints with stainless steel bolts in fire
}

\author{
N. Satheeskumar · J. B. Davison
}

Received: 22 October 2014/Accepted: 5 November 2014/Published online: 12 November 2014

(C) The Author(s) 2014. This article is published with open access at Springerlink.com

\begin{abstract}
The robustness of steel joints in fire is important for steel building structures because of the need to prevent progressive collapse. Stainless steel is widely used in building construction mainly because of its corrosion resistance, but it also possesses improved fire resistance compared with conventional non-alloy, fine grain structural steels. Extensive research performed on the robustness of steel joints in fire has revealed that failure at elevated temperature may be controlled by bolt shear for fin plate and web cleat connections. Hence, this study focussed on the use of stainless steel in experimental tests conducted on fin plate and web cleat connections at high temperatures. In addition, this study investigated the use of a component-based model to predict connection performance at elevated temperature.
\end{abstract}

Keywords Steel joints - Stainless steel joint - Web cleat connection $\cdot$ Fin plate connection $\cdot$ Robustness

\section{Introduction}

Non-residential multi-storey buildings often use a steelframed structure and steel-concrete composite floor and beams because of speed of construction, low cost, lighter

\footnotetext{
N. Satheeskumar $(\square)$

School of Engineering and Physical Sciences, James Cook University, Angus Smith Drive, Douglas, Townsville, QLD 4811, Australia

e-mail: navaratnam.satheeskumar@my.jcu.edu.au

\section{J. B. Davison}

Department of Civil and Structural Engineering, The University of Sheffield, Sir Frederic Mappin Building, Mappin Street, Sheffield S1 3JD, UK

e-mail: j.davison@sheffield.ac.uk
}

weight and low maintenance cost when compared to a concrete structure. The performance of steel-framed structures in fire, although now well understood and accounted for in design and construction by a range of approaches, remains a cause of concern for designers in some parts of the world. The damaging effect of fire and resulting collapse of a number of buildings at the World Trade Center (New York) in 2001 focussed attention on the need to ensure robustness in steel-framed buildings under extreme conditions.

Current design codes generally consider that steel connections will be heated more slowly than beams or columns in fire situations, therefore reducing the likelihood that they will be the critical components in fire safety design (Al-Jabri et al. 2008). In the UK, connections in structural steel are designed to transfer shear (and sometimes moment) at ambient temperature and also resist an axial force, known as a tying force, under accidental loading conditions (Way 2011). In fire, the joints experience additional compressive or tensile forces due to restraint to thermal expansion or to catenary action arising from large deflections (Yu et al. 2009). Connection failures could lead to progressive collapse of a building. The term of progressive collapse is "the spread of an initial local failure from element to element, eventually resulting in the collapse of an entire structure or a disproportionately large part of it." (UFC 2009). Therefore, it is essential that the structural elements and the connections between them have the ability to resist a degree of damage in order to prevent progressive collapse. This inherent characteristic of a well-designed structure is referred to as robustness.

The term Robustness is defined as the "ability of a structure to withstand events like fire, explosions, impact or the consequences of human error, without being damaged to an extent disproportionate to the original cause" (CEN 2002). The "Tying force" approach is one of the design methods used to provide a measure of resistance to 
Fig. 1 The experimental test arrangement

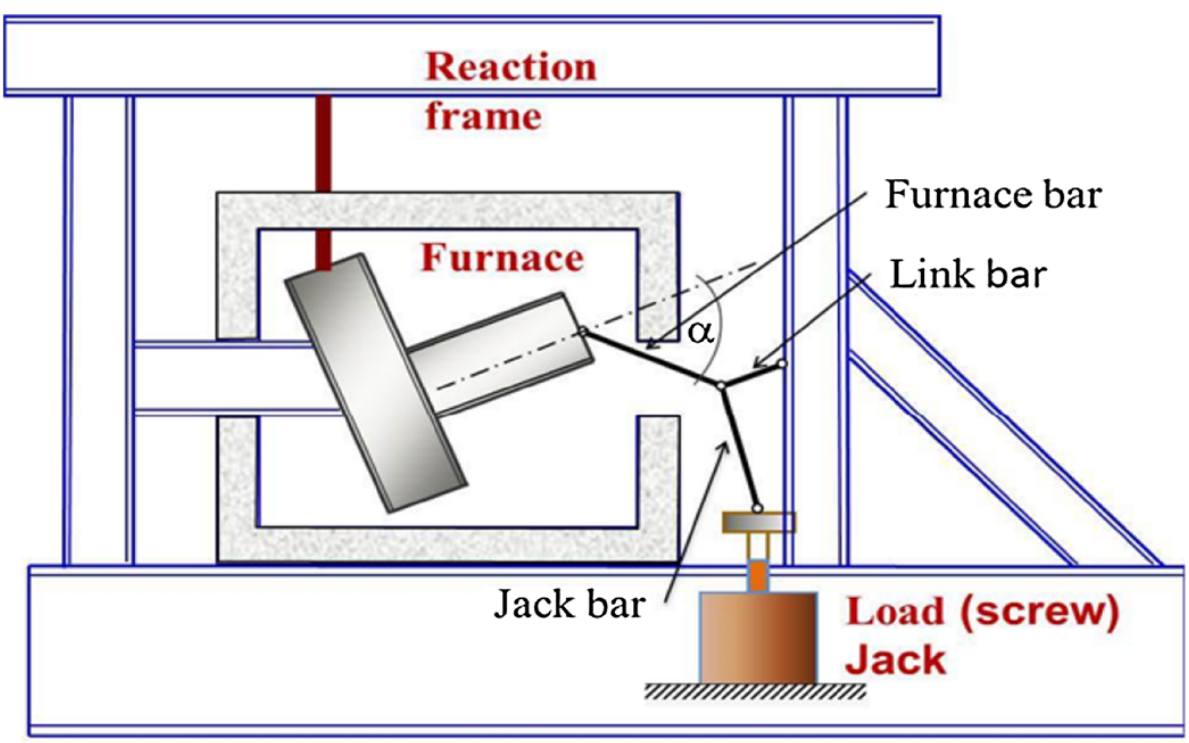

progressive collapse. The term can be explained as "tying a steel frame horizontally and vertically to increase its structural continuity and create a structure with a high level of robustness" (Yu et al. 2009). The ability to resist a tying force is called tying resistance. The tying force generated in a structural member (beam, column) must be conveyed through the connection.

Research reported by Yu et al. $(2009,2009)$ considered the elevated temperature robustness of fin plate and web cleat connections. These studies highlighted the important role played by the bolts and demonstrated that in many cases, bolt failure became critical at elevated temperatures.

Stainless steel is widely used as an alternative to mild steel for secondary steel work and fittings in building construction because of its corrosion resistance, ease of maintenance and aesthetic appearance. Stainless steel also offers improved fire resistance, although this is rarely a reason for choosing the material in structural applications. However, this study sought to investigate the benefits of replacing ordinary structural bolts with stainless ones in joints subjected to high temperatures.

In this investigation, the test specimens were assembled using stainless bolts in a fin plate and web cleat connections which were identical to those tested by $\mathrm{Yu}$ et al. The experimental test results are compared with the results and conclusions of the earlier experiments by $\mathrm{Yu}$ (Yu et al. 2009, 2009) and also with component-based model analysis.

\section{Experimental set-ups}

The tests were carried out on typical beam-to-column connections at a constant elevated temperature in an electrically heated furnace. The temperature distribution around the joint was measured using thermocouples which are located at the beam flange, beam web, column flange, and fin plate and web cleat angles. The specimens were heated to a specified temperature $(550$ or $650{ }^{\circ} \mathrm{C}$ ) and tested at that constant temperature. The load was applied through three, linked, strain-gauged Macalloy bars so the load applied through the loading bar could be determined as shown in Fig. 1. The changes in inclination of these three bars were recorded using three angular transducers and a digital camera. The deformation of the specimen was recorded using digital cameras and then determined by using image recognition software. Figure 1 also shows the load angle $(\alpha)$ between the furnace bar and the beam axis determined the shear to tensile force ratio applied to the connection.

A $254 \times 89 \mathrm{~kg} / \mathrm{m}$ universal column section in grade $\mathrm{S}$ 355 was used for the column and a $305 \times 165 \times 40 \mathrm{~kg} / \mathrm{m}$ universal beam section in grade S 275 was used for the beam; these sections were used in all the experimental tests. A $20 \mathrm{~mm}$ thick ceramic fibre blanket was wrapped around the beam and column but not around the connection zone (i.e. fin plate, web cleat angle, column flange, and bolts and beam web). The connection zones are exposed to heat throughout the testing.

Details of fin plate connection

Figure 2 shows the geometry of the fin plate connection test specimen. The fin plate was $10 \mathrm{~mm}$ thick mild steel and all the bolts were $20 \mathrm{~mm}$ diameter austenitic 


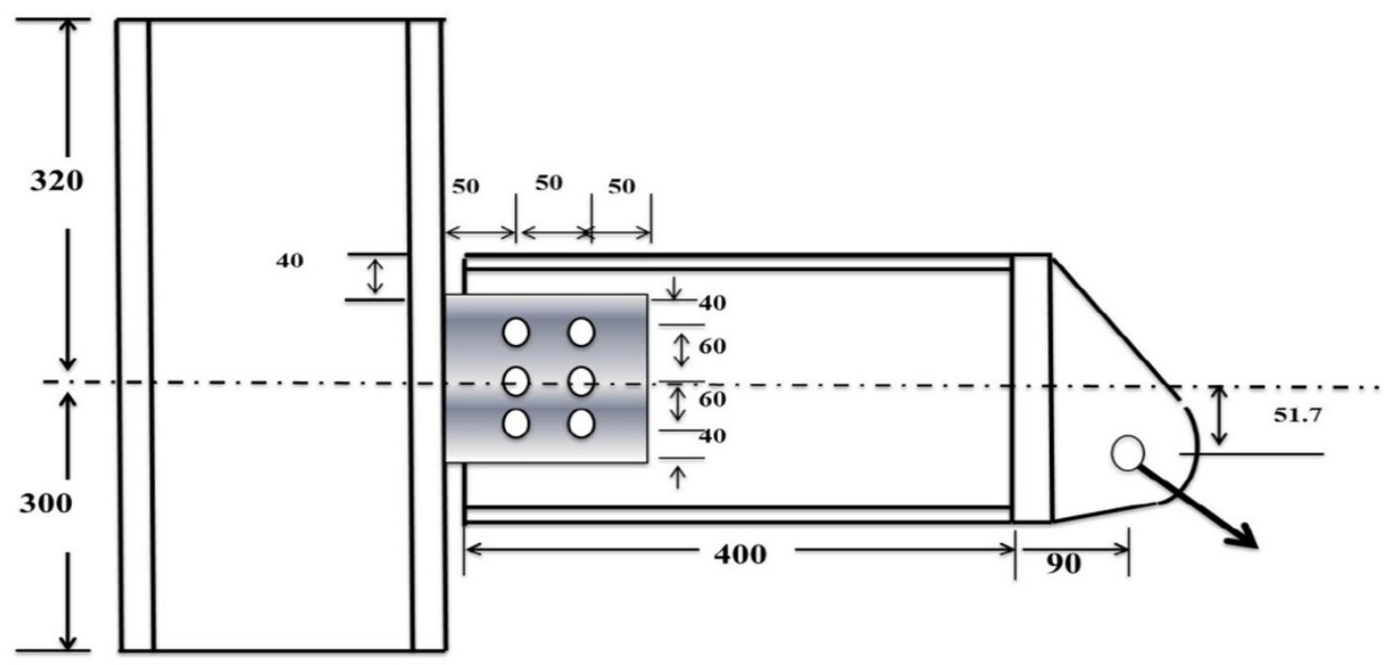

Fig. 2 Fin plate connection details

Fig. 3 Web cleat connection details

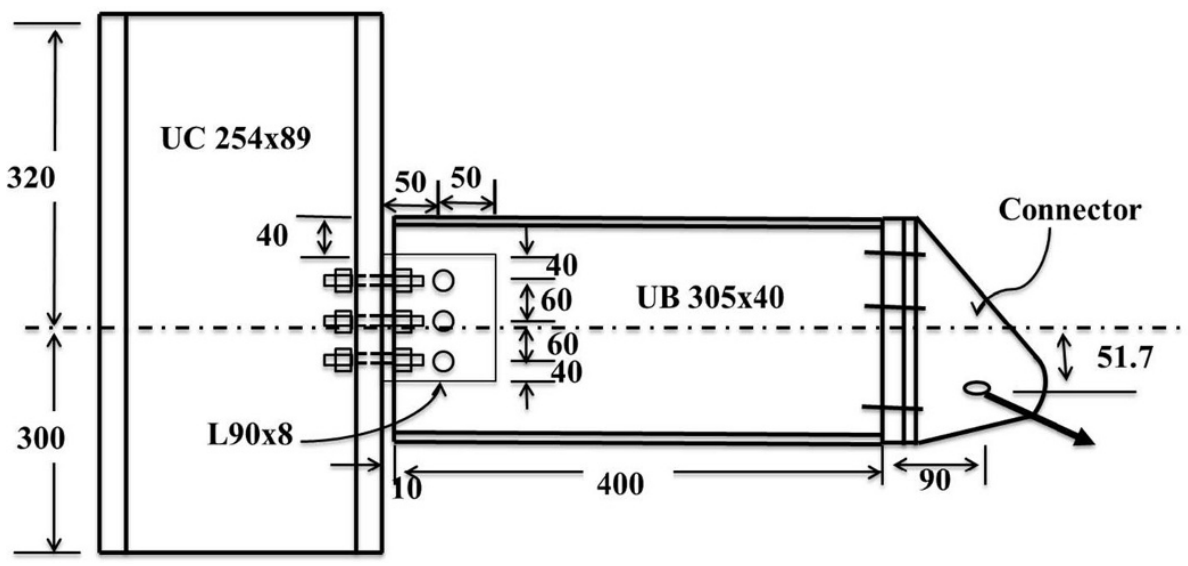

stainless steel of property class 80 . The specimen was tested at a temperature $550{ }^{\circ} \mathrm{C}$ and load angle $(\alpha$, see Fig. 1) of $55^{\circ}$.

Details of web cleat connection

The web cleat connection consisted of double angle L90 $\times 90 \times 8$ sections in S 275 as shown in Fig. 3. Three 20-mm diameter austenitic stainless steel bolts in property class 80 were used through the beam web and six $20-\mathrm{mm}$ diameter ordinary bolts in grade 8.8 were connected to the column flange (the reason that grade 8.8 bolts were used in the flange is because the failure mode in earlier tests ( $\mathrm{Yu}$ et al. 2009) was in the bolts in the beam web, that is, the column flange bolts were not critical). The test was conducted at a temperature of $650{ }^{\circ} \mathrm{C}$ and the load angle $(\alpha$, see Fig. 1) of $55^{\circ}$.
Component-based model assembly

Component-based model assembly for fin plate connection

The component-based model for the fin plate connection is constructed as an assembly of spring elements as shown in Fig. 4. This model uses a component-based model approach developed by Sarraj et al. (2007) for a single line of bolts in the connection. In the current analysis, a double line of bolts was used in the connection. The active joint components are the fin plate in bearing, beam web in bearing, bolts in single shear, beam web-to-fin plate in friction and weld in tension. This model was simplified via a series of lap joints attached to each other in parallel (Fig. 4). Figure 5 illustrates the lap joints of the fin plate connection under tying force. All active joint components are represented by a spring and the force-displacement relationship of each was calculated according to Sarraj 
Fig. 4 Component-based model for fin plate connection
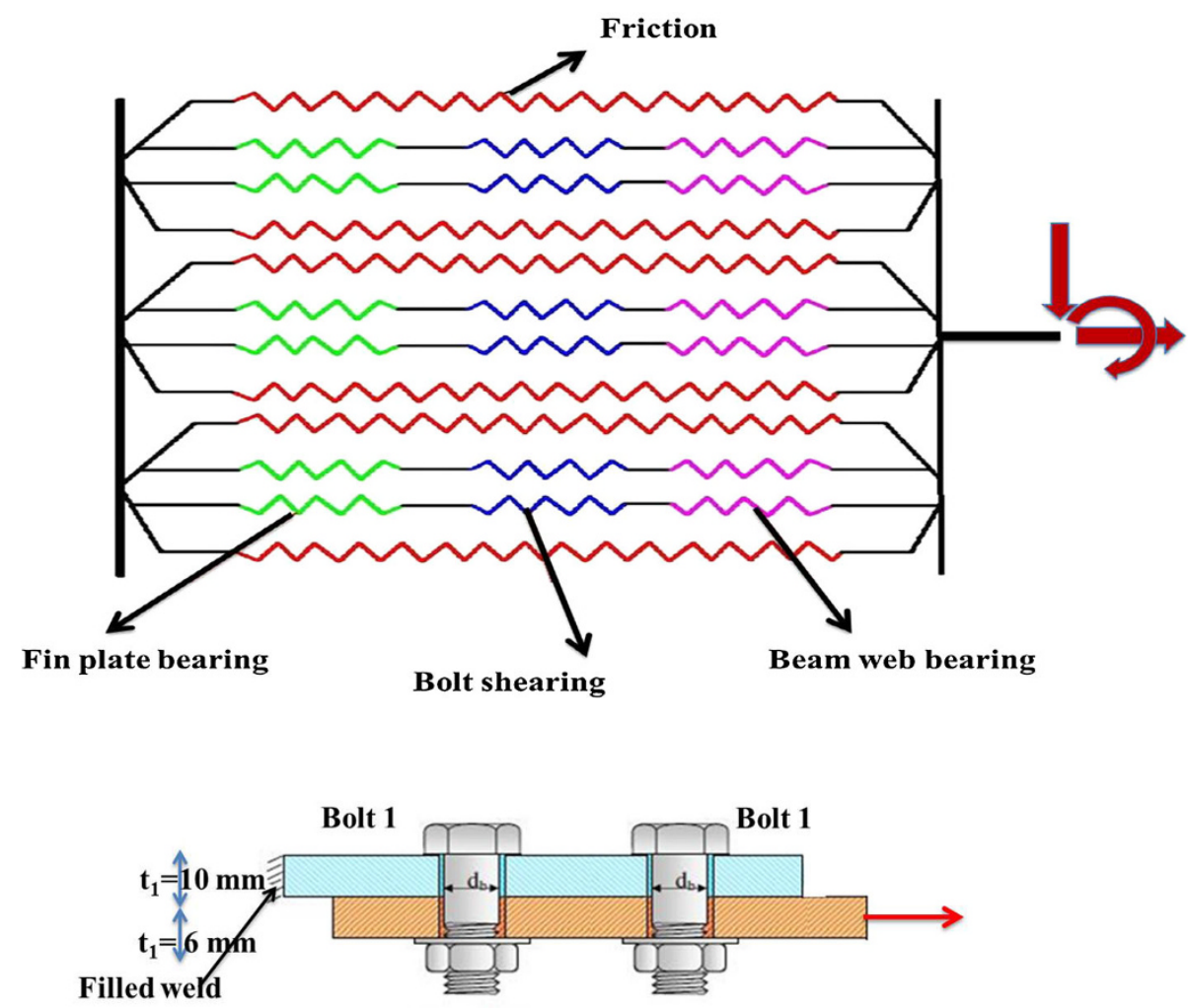

Fig. 5 Lap joint of fin plate component model

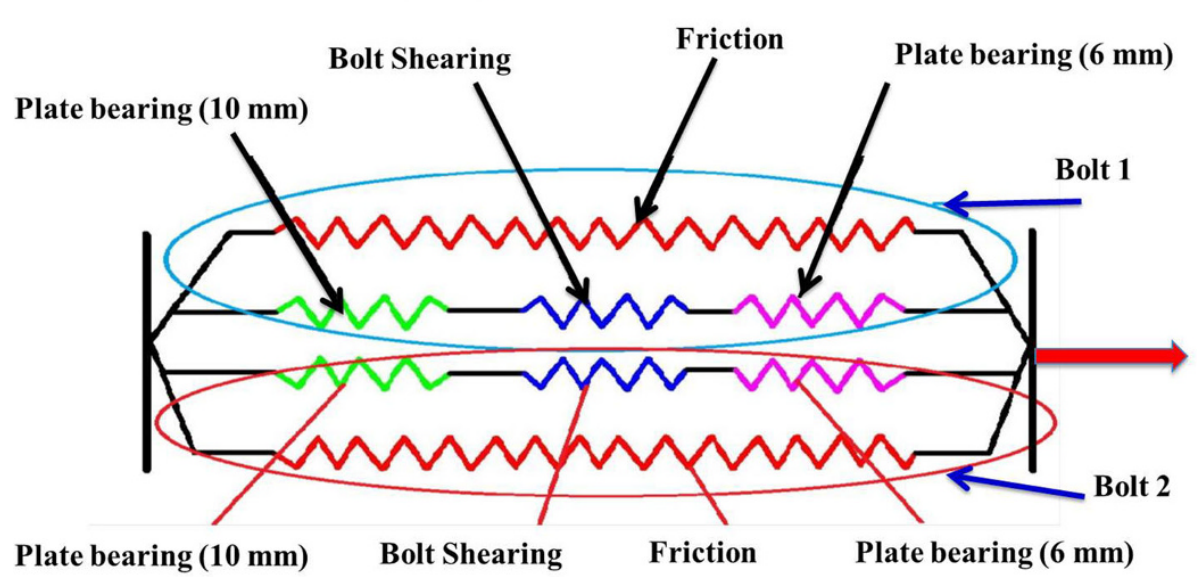

et al. (2007) component-based model analysis. These calculated force-displacement relationships were introduced into the general FEM program ABAQUS simply as properties of spring elements.

\section{Component-based model assembly for web cleat connection}

A component-based model analysis that was developed by $\mathrm{Yu}$ et al. (2009) was used in this study. Yu's research identifies four active components in the typical web cleat connection: bolts in tension, web cleats in bending, bolts in shear and beam web in bearing. These active components are assembled as a four-spring system in each series of bolt rows as shown in Fig. 6. Yu's research also investigated the non-linear load and displacement response of web angles under tensile loading. The current study has used $\mathrm{Yu}$ et al. (2009) component-based model. The material properties and the force-displacement characteristics of the bolts in double shear were modified to account for the use of stainless steel. The force-displacement relationships of each spring were calculated and introduced into the general FEM program ABAQUS simply as properties of spring elements.

Experimental results

The experimental results for the fin plate connection and web cleat connection tests have been summarized in 
Fig. 6 Component-based model for web cleat connection

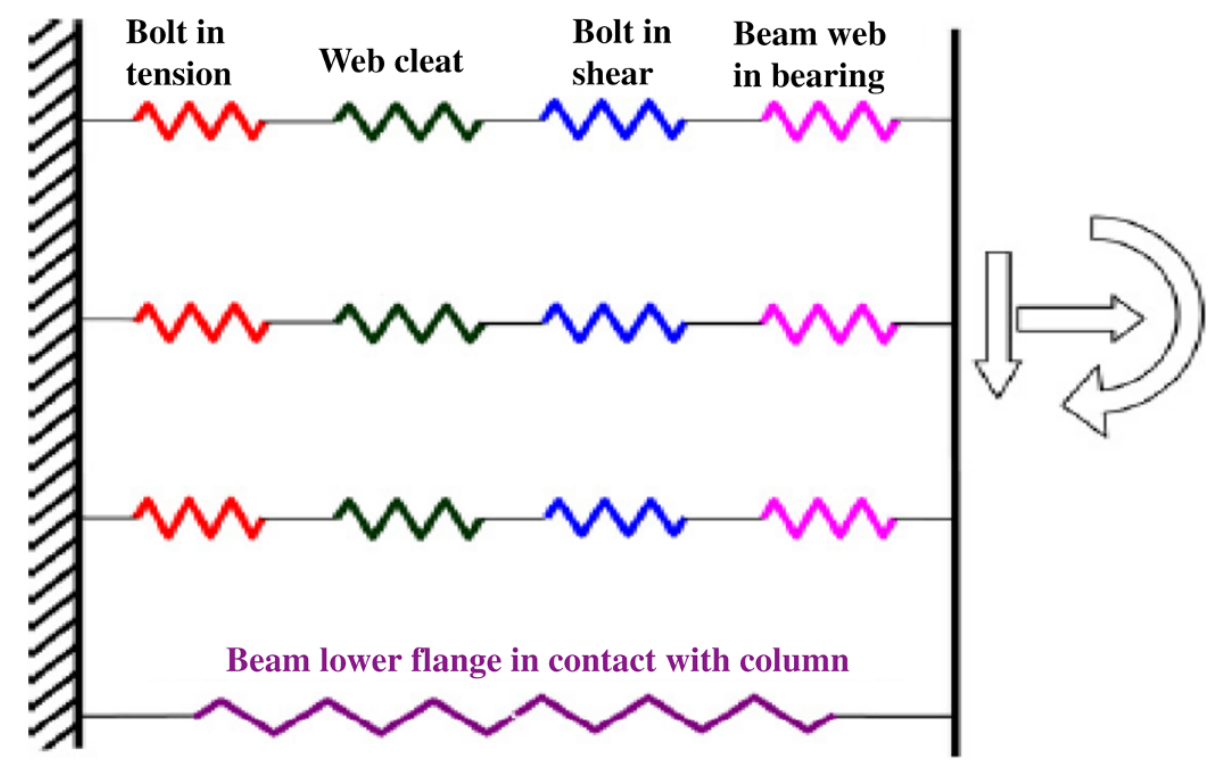

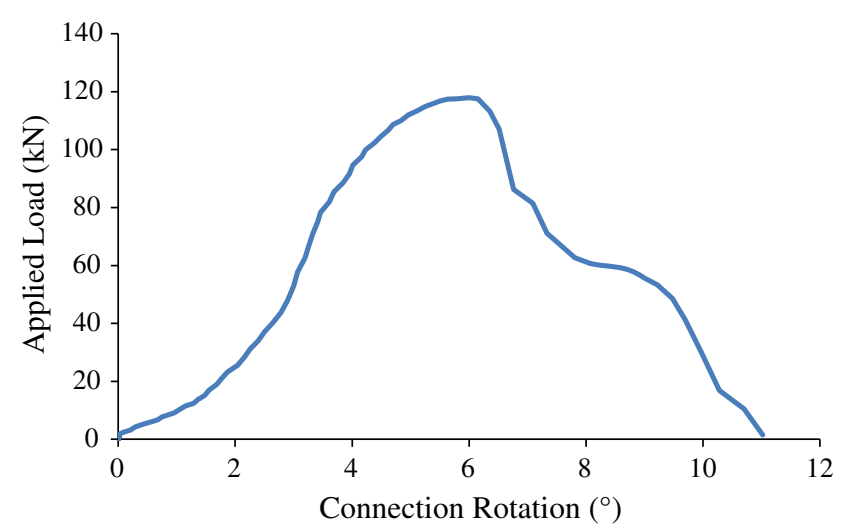

Fig. 7 The force-rotation relationships for fin plate connection at $550{ }^{\circ} \mathrm{C}$

Figs. 7 and 8 including the variations of the connection rotation and force. Figure 7 shows the force-rotation relationships for the fin plate connection at $550{ }^{\circ} \mathrm{C}$ and load angle of $55^{\circ}$. It shows the maximum failure load of the fin plate connection at $550{ }^{\circ} \mathrm{C}$ is $118 \mathrm{kN}$ at a connection rotation of $6^{\circ}$.

Figure 8 shows the variation of applied force versus connection rotation for the web cleat connection at $650{ }^{\circ} \mathrm{C}$ and load angle of $55^{\circ}$. It shows that the maximum failure load of the web cleat connection at $650{ }^{\circ} \mathrm{C}$ is $28 \mathrm{kN}$ at a connection rotation of $10^{\circ}$.

Comparison of experimental tests results

Experimental test failure modes and force-rotation relationships and component-based model results of connections are compared with previous research results. Figure 9

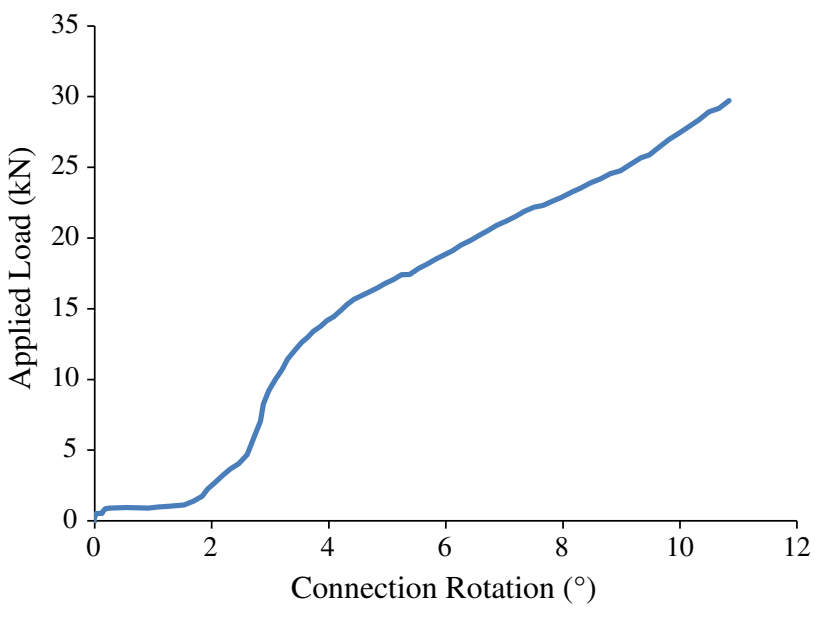

Fig. 8 The force-rotation relationships for web cleat connection at $650{ }^{\circ} \mathrm{C}$

illustrates the comparison of the force-rotation relationship of the component-based model with the experimental test results of the fin plate connection. It shows the maximum failure load of the component-based model is $130 \mathrm{kN}$ at a connection rotation of $7.3^{\circ}$ and the component-based simple model gives a reasonable prediction of the response of the fin plate connection in fire. The robustness of the connection, as defined by its tying resistance, is specified to be a minimum of $75 \mathrm{kN}$ (BSI 1990). At $550{ }^{\circ} \mathrm{C}$, the fin plate connection failure happened at a failure load that was less than $75 \mathrm{kN}$ in Yu's test (Yu et al. 2009). In the current experiment with stainless steel bolts, the connection failure load was greater than the minimum tying force and approximately two times higher than ordinary steel bolt fin plate connection at elevated temperature. 


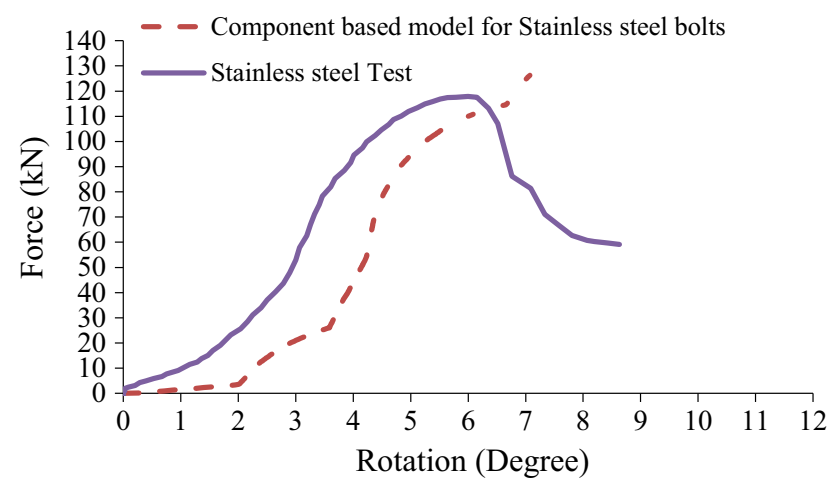

Fig. 9 The comparison of force-rotation relationships of fin plate connection at temperature $550{ }^{\circ} \mathrm{C}$

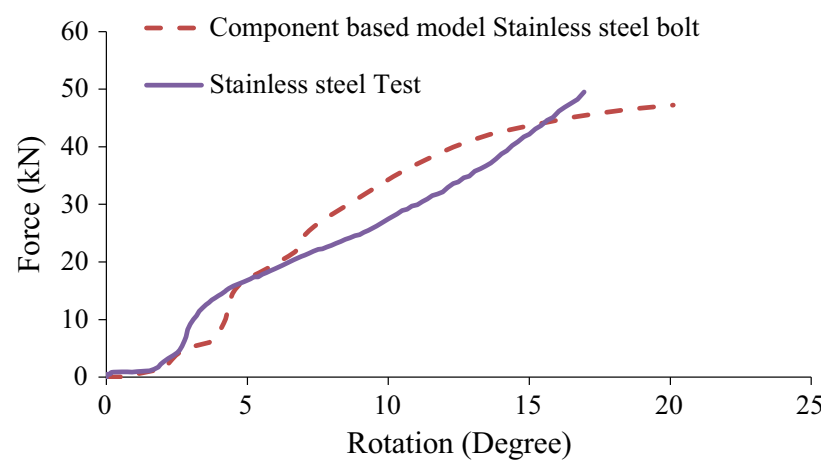

Fig. 10 The comparison of force-rotation relationships of web cleat connection temperature $650{ }^{\circ} \mathrm{C}$

The failure mode in this study was weld fracture. Normally, weld fracture is not critical for a fin plate connection. The reduction in weld strength at high temperature was proportionally greater than that in the stainless steel bolts; thus the mode of failure transferred from plate bearing at room temperature to weld fracture at high temperature.

Figure 10 shows the comparison of force-rotation relationship of the component-based model with the experimental test results of the web cleat connection. It shows that the response of the component-based model is similar to the experiments of the web cleat connection. However, the maximum failure load and connection rotation of the component-based model are slightly different from the experimental test results. The maximum failure load in this experiment was nearly two times higher than Yu's (Yu et al. 2009) test results. This clearly indicated that the tying resistance of web cleat connection with stainless steel bolts connection is higher than web cleat connection with ordinary bolts. This also showed that the connection performance and robustness at elevated temperature improved when adopting stainless steel bolts in the connection.
In this connection, two types of failure mode were found as follows: two web cleat angles underwent significant amounts of deformation and the top two bolts connected to the column flange were deformed as shown in Fig. 11. This fracture happened due to a very high rotation of this connection. This type of failure in the web cleat connection depends on temperature and rotation of connection.

\section{Prediction of the maximum failure load}

The component-based model analysis of the model gives a reasonable structural response to the fin plate connection and web cleat connection. Based on the component-based model analysis of the model, this study predicts the maximum failure load of different types of connections. This study involved eight simple models using the fin plate connection and eight simple models using the web cleat connection. One of the assumptions made in this analysis is that the temperature distribution is uniform. Those models are based on the model specifications detailed in Sects. 2.3.1 and 2.3.2. However, this model is separated into two types: connection with ordinary bolts and with stainless steel bolts. Each category has four different beam sections and four different numbers of bolts' rows. The above-detailed model used the same column section, i.e. $254 \times 254 \times 89$ UC S355. The component-based results are compared with experimental results. Figures 12 and 13 show the comparison of the force-rotation relationship for the fin plate connection and web cleat connection with the experimental test results. This figures also indicated that the component-based model results have given an acceptable prediction of the test behaviour. Based on this, the study predicts different connections maximum failure load at elevated temperature as shown in Tables 1 and 2.

\section{Conclusions}

The response of the fin plate connection and web cleat connection using stainless steel bolts to improve robustness in fire has been studied using experimental tests and component-based model analysis. The outcomes of this study will be used to assess the vulnerability of the fin plate connection and web cleat connection during fire hazards.

The experimental results show that the maximum failure load of stainless steel bolted connections is higher than connections with ordinary high strength $(8.8)$ bolts. The study indicates that the adoption of stainless steel bolts connection could improve the robustness of the fin plate and web angle connections in fire.

The component-based model gives a reasonable prediction of connection performance with both 8.8 and 
Fig. 11 The failure modes of a Fin plate b Web cleat connections (a)

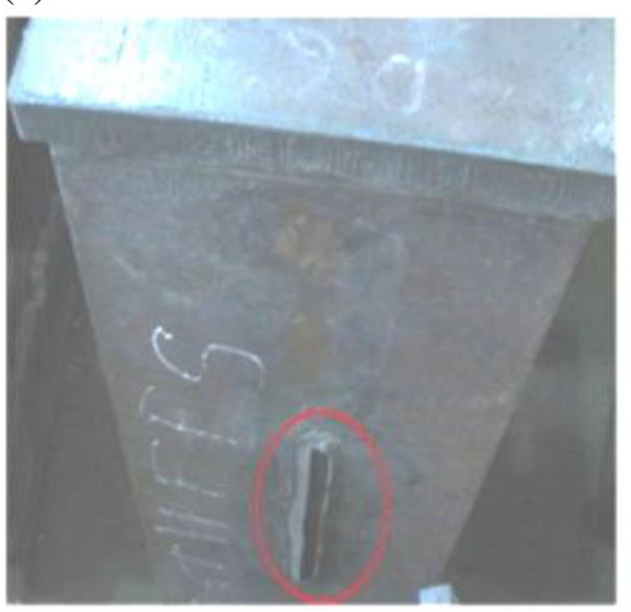

Bolts failure

(b)

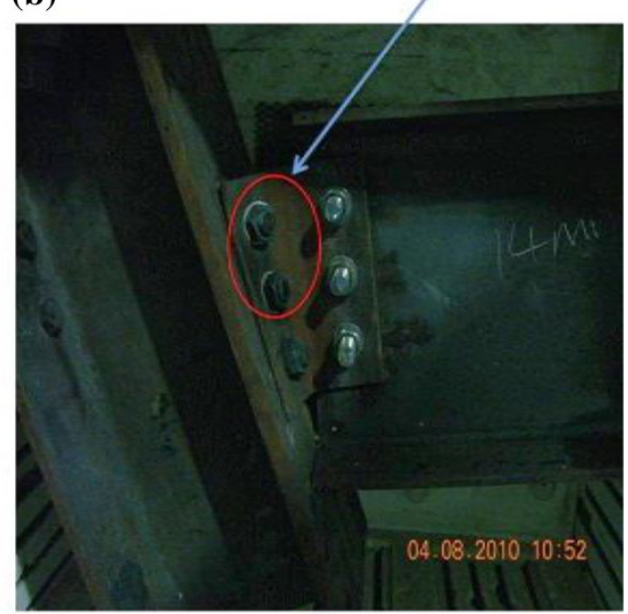

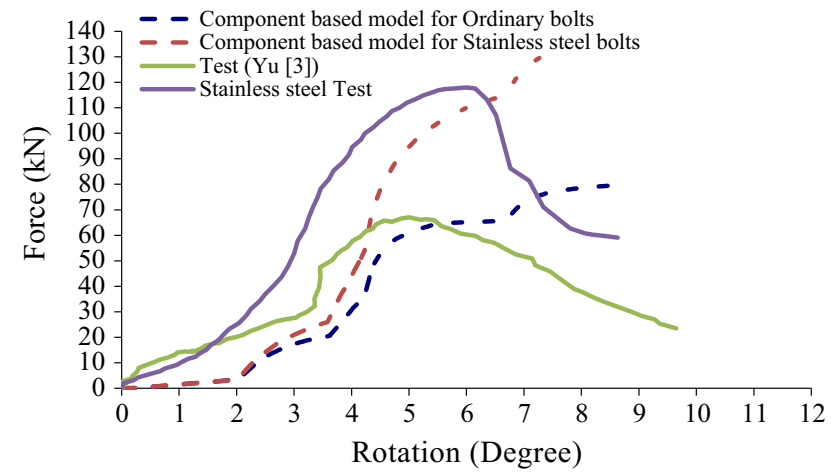

Fig. 12 The comparison of force-rotation relationship of componentbased model for fin plate connection at $550{ }^{\circ} \mathrm{C}$

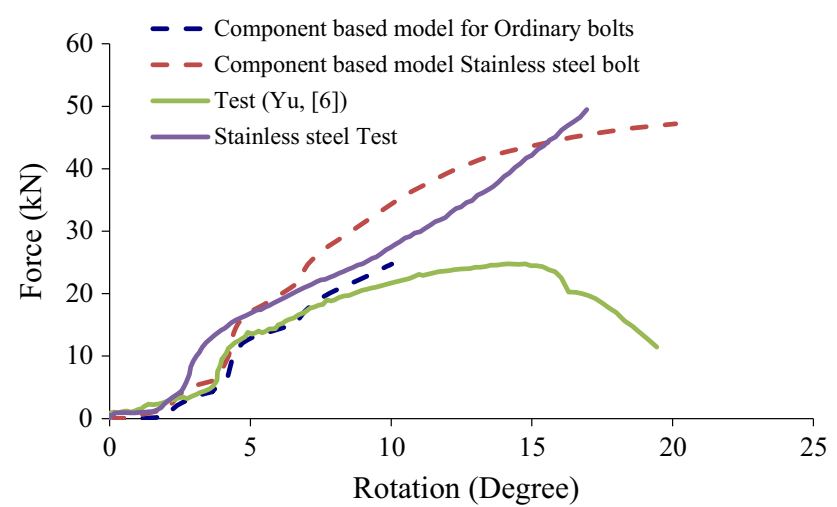

Fig. 13 The comparison of force-rotation relationship of componentbased model for web cleat connection at $650{ }^{\circ} \mathrm{C}$

stainless bolts. The component-based design method is an alternative method to assess the robustness of a connection in design practice. A comparison was made of the potential
Table 1 The prediction of maximum load for fin plate connection at temperature $550{ }^{\circ} \mathrm{C}$

\begin{tabular}{|c|c|c|c|c|}
\hline \multicolumn{5}{|c|}{ Fin plate, double line of bolts } \\
\hline \multicolumn{5}{|c|}{$150 \times 10 \mathrm{~mm}$ fin plate in $\mathrm{S} 275$} \\
\hline $\begin{array}{l}\text { Beam size (UB, } \\
\text { S275) }\end{array}$ & Bolt rows, $n$ & $\begin{array}{l}F_{8.8} \\
(\mathrm{kN})\end{array}$ & $\begin{array}{l}F_{\mathrm{ss}} \\
(\mathrm{kN})\end{array}$ & $\begin{array}{l}L_{\mathrm{F}} \\
(\mathrm{mm})\end{array}$ \\
\hline $406 \times 178 \times 54$ & 4 & 125.19 & 250.26 & 260 \\
\hline $457 \times 152 \times 52$ & 5 & 168.94 & 325.03 & 320 \\
\hline $533 \times 210 \times 82$ & 6 & 229.42 & 437.95 & 380 \\
\hline
\end{tabular}

Table 2 The prediction of maximum load for web cleat connection at temperature $650{ }^{\circ} \mathrm{C}$

Double angle cleat, single line of bolts

2 No. $90 \times 90 \times 8 \mathrm{~mm}$ equal angle in S275

\begin{tabular}{lllll}
\hline Beam size $(\mathrm{UB}, \mathrm{S} 275)$ & Bolt rows, $n$ & $F_{8.8}(\mathrm{kN})$ & $F_{\mathrm{ss}}(\mathrm{kN})$ & $l_{\mathrm{a}}(\mathrm{mm})$ \\
\hline $305 \times 165 \times 40$ & 3 & 24.74 & 47.22 & 200 \\
$406 \times 178 \times 54$ & 4 & 36.80 & 65.89 & 260 \\
$457 \times 152 \times 52$ & 5 & 37.79 & 84.13 & 320 \\
$533 \times 210 \times 82$ & 6 & 62.84 & 121.68 & 380 \\
\hline
\end{tabular}

$F_{8.8}$ maximum force in ordinary bolt connection

$F_{s s}$ maximum force in stainless steel bolt connection

$l_{F}$ fin plate length

$l_{a}$ angle cleat length

for improved connection performance if stainless steel bolts were used. It is recommended based on this study and earlier investigations:

- To improve the performance of conventional steel connections, stainless steel bolts could be used to avoid bolt shear failure and change the failure mode to web bearing. 
- The fin plate connection with stainless steel bolts would need to be designed to avoid brittle failure models at elevated temperature such as weld fracture.

Acknowledgments The authors gratefully acknowledge the assistance provided by Dr Shan-Shan Huang in conducting the experiments and the support of the technical staff in the Heavy Structures Laboratory at the University of Sheffield.

Open Access This article is distributed under the terms of the Creative Commons Attribution License which permits any use, distribution, and reproduction in any medium, provided the original author(s) and the source are credited.

\section{References}

Al-Jabri KS, Davison JB, Burgess IW (2008) Performance of beamto-column joints in fire, A review. Fire Saf J 43(1):50-62

BSI (1990) BS5950: Part 1:1990 structural use of steelwork in building-Part1: code of practice for design in simple and continuous construction: hot rolled sections. British Standards Institution, London
CEN (2002) BS EN 1990:2002 Eurocode 0: basis of structural design. European Committee for Standardisation, Brussels

Jaspart JP, Demonceau JF (2008) European design recommendations for simple joints in steel structures. J Constr Steel Res 64:822-832

Sarraj M, Davison JB, Burgess IW, Plank RJ (2007) Finite element modelling of fin plate steel connections in fire. Fire Saf J $42: 408-415$

UFC 4-023-03 (2009) Unified Facility Criteria (UFC) design of buildings to resist progressive collapse, Approved for public release, Distribution unlimited pp12

Way AGJ (2011) Structural robustness of steel framed buildings. Publication P391, The Steel Construction Institute, Ascot

Yu HX, Burgess IW, Davison JB, Plank RJ (2009a) Experimental investigation of the behaviour of fin plate connections in fire. J Constr Steel Res 65:723-736

Yu HX, Burgess IW, Davison JB, Plank RJ (2009b) Tying capacity of web cleat connections in fire. Part 1: test and finite element simulation. Eng Struct 31(3):651-663

Yu HX, Burgess IW, Davison JB, Plank RJ (2009c) Tying capacity of web cleat connections in fire. Part 2: development of componentbased model. eng Struct 31(3):697-708 